\title{
ROLE OF ORAL MISOPROSTOL 25 MG (MICROGRAM) IN PREMATURE RUPTURE OF MEMBRANE IN PATIENT AT TERM
}

\author{
Nitu Singh', Prashant Uikey², Chandni Bagga ${ }^{3}$ \\ ${ }^{1}$ Senior Resident, Department of Obstetrics and Gynaecology, Indira Gandhi Government Medical College and Hospital, Nagpur. \\ 2Professor and HOD, Department of Obstetrics and Gynaecology, Indira Gandhi Government Medical College and Hospital, Nagpur. \\ ${ }^{3} 3^{\text {rd }}$ Year Junior Resident, Department of Obstetrics and Gynaecology, Indira Gandhi Government Medical College and Hospital, Nagpur.
}

\section{ABSTRACT}

\section{BACKGROUND}

Premature rupture of membranes is a potential hazard in obstetrics. It causes significant maternal and neonatal morbidity. ${ }^{1,2}$ It complicates $5-10 \%$ of all pregnancies at term. ${ }^{3}$ and therefore warrants intervention; 25 microgram misoprostol is a promising agent for induction of labour in PROM.

\section{METHODS}

A prospective study was carried out in 100 cases with premature rupture of membranes at term satisfying the inclusion and exclusion criteria. They were divided into study and control group. Study group was given 25 microgram misoprostol orally, which was repeated every 4 hourly till maximum of 6 doses till onset of active labour. Control group was managed by traditional method (Oxytocin infusion for augmentation of labour). The mode of delivery and the induction delivery time was noted. The maternal and neonatal morbidity was also noted.

\section{RESULT}

Average induction delivery interval in misoprostol group was $10.01 \pm 3.08 \mathrm{hrs}$. and $14.15 \pm 5.30 \mathrm{hrs}$. in control groups (P=0.0006). Average PROM delivery interval in misoprostol group was $13.58 \pm 3.49 \mathrm{hrs}$. and $18.19 \pm 5.62 \mathrm{hrs}$. in control group ( $\mathrm{P}=0.000)$; $64 \%$ of patients delivered vaginally as compared to $70 \%$ in control group and caesarean rate was $28 \%$ as compared to $24 \%$ in control group.

\section{CONCLUSION}

Tab Misoprostol in a dose of 25 micrograms in cases of premature rupture of membrane at term reduces the induction delivery interval and thus reduces maternal and perinatal morbidity associated with PROM.

\section{KEYWORDS}

PROM, Misoprostol, Induction Delivery Interval.

HOW TO CITE THIS ARTICLE: Singh N, Uikey P, Bagga C. Role of oral misoprostol $25 \mathrm{mg}$ (microgram) in premature rupture of membrane in patient at term. J. Evolution Med. Dent. Sci. 2016;5(43):2669-2672, DOI: 10.14260/jemds/2016/625

\section{INTRODUCTION}

Premature rupture of membrane is a common clinical event affecting $5-10 \%$ of pregnancies, which can turn a normal pregnancy into a high risk situation for both the mother and fetus. Under normal circumstances, the foetal membranes rupture during the active phase of labour. Premature rupture of membranes is defined as rupture of membranes before onset of labour.

Premature rupture of membranes is usually associated with prolonged labour. It leads to increased maternal and perinatal morbidity. Early delivery leads to problem of prematurity and on the other hand prolongation of pregnancy involves the risk of chorioamnionitis, funisitis, dry labour, placental abruption in the mother and sepsis, respiratory distress syndrome, intraventricular haemorrhage in the newborn. 4,5

\section{Financial or Other, Competing Interest: None.}

Submission 03-03-2016, Peer Review 22-04-2016,

Acceptance 28-04-2016, Published 28-05-2016.

Corresponding Author:

Dr. Nitu Singh,

$\# B$ 6,

Nanak Shilp Society,

Smruti Nagar,

Koradi Road,

Nagpur-441111.

E-mail: ajayneetu@rediffmail.com

DOI: $10.14260 /$ jemds $/ 2016 / 625$
Existing views differ widely regarding the timing and method of induction of labour in PROM at term. Hence, the management of premature membranes presents a dilemma to the obstetrician. The advent of prostaglandin analogue, misoprostol has given the obstetrician another alternative to the traditional use of oxytocin for active management of PROM. Prostaglandins are used in obstetrics because of their uterotonic and cervical ripening effect.

In the management of premature rupture of membranes at term an active approach is desirable, because a prolonged PROM delivery interval is associated with increased incidence of chorioamnionitis. However, induction of labour in the presence of unfavourable cervix is associated with an increased chance of failed induction and an increased rate of caesarean delivery. Thus, it is important to ripen the cervix before induction in order to improve the chance of successful vaginal delivery.

Prostaglandin E2 applied intracervically. ${ }^{6,7}$ for ripening is unstable at room temperature as well as may lead to ascending infection. As well as they are not superior to IV oxytocin. Oxytocin has been used as a traditional method for augmentation of labour. Oral misoprostol tablets are stable, affordable and can be given orally, hence minimising the risk of infection.

So in this study, we have compared the role of oral misoprostol 25 microgram in PROM patients as compared to IV oxytocin infusion for labour induction at term. 


\section{MATERIAL AND METHODS}

It was a hospital based study. Total 100 subjects diagnosed as cases of PROM by evaporation test were selected as per inclusion and exclusion criteria described below after obtaining written informed consent.

\section{Inclusion Criteria}

- Singleton pregnancy with vertex presentation with no added obstetrics complications.

- Women sure of date of last menstrual period.

- History suggestive of Premature Rupture of Membrane (PROM).

- Absence of active uterine contractions.

- Demonstration of leaking per vaginum on speculum examination.

\section{Exclusion Criteria}

- Women with previous uterine surgeries.

- Multiple pregnancies.

- Women with non-vertex presentation.

- Features of chorioamnionitis.

- Severe gestational hypertension.

- Grand multiparity.

- Antepartum haemorrhage.

Complete maternal examination was done. Per vaginal examination was done to note cervical effacement and dilatation, presentations and position of the foetus and the presence or absence of membranes. Evaporation test was done as follows - A high cervical swab was taken on glass slide with sterile stick and heated. After evaporation if amniotic fluid is present, the residue turns white or grey (Test is taken as positive), else it turns brown. After proper assessment, patients of study group were given 25 micrograms oral misoprostol at 4 hourly interval up to a maximum of 6 doses. Control group patients were managed by the traditional method by oxytocin drip given for induction or acceleration of labour.

A Cardiotocography (CTG) was done before each dose of misoprostol and the control group was monitored as per regular hospital protocols. Women who went into active labour had vaginal examination at 4-6 hour interval. If after six doses the women did not go into active labour, the induction was considered as failed.

Both the groups were given antibiotics like ampicillin/amoxicillin and were monitored for foetal distress, tachysystole, hyperstimulation and progress of labour.

The mode of delivery was noted either vaginal delivery (Including instrumental delivery) or caesarean section. Induction delivery interval was noted. Foetal outcome in terms of date and time of delivery, sex and weight of baby, live or stillbirth, Apgar score at 1 minute and 5 minutes after delivery was recorded. Maternal outcome in terms of nausea vomiting, loose motions, fever, PPH, uterine tachysystole, blood transfusion and puerperal sepsis were considered.

\section{OBSERVATION}

\begin{tabular}{|c|c|c|c|c|}
\hline \multirow{2}{*}{$\begin{array}{c}\text { Bishop } \\
\text { Score }\end{array}$} & \multicolumn{2}{|c|}{ Study Group } & \multicolumn{2}{c|}{ Control Group } \\
\cline { 2 - 5 } & PRIMI & Multi & PRIMI & Multi \\
\hline$<3$ & 18 & 2 & 11 & 3 \\
\hline $3-6$ & 13 & 15 & 22 & 13 \\
\hline$>6$ & 0 & 2 & 0 & 1 \\
\hline
\end{tabular}

\begin{tabular}{|l|c|c|c|c|}
\hline Total & $\mathbf{3 1}$ & $\mathbf{1 9}$ & $\mathbf{3 3}$ & $\mathbf{1 7}$ \\
\hline $\begin{array}{l}\text { Mean } \\
\text { Score }\end{array}$ & $3 \pm 1.51$ & $3.22 \pm 0.92$ & $3.75 \pm 1.67$ & $3.35 \pm 0.99$ \\
\hline \multicolumn{4}{|c|}{ P value $=0.1286$ NS } & \multicolumn{2}{|c|}{ P value $=0.3662 \mathrm{NS}$} \\
\hline \multicolumn{4}{|c|}{ According to Bishop Score } \\
\hline
\end{tabular}

From this table, it is evident that maximum patients had Bishop score of 3-6, i.e. 28 (56\%) in study group as compared to $35(70 \%)$ in control group indicating an unripe cervix and therefore ripening of cervix with induction of labour is required in PROM patients.

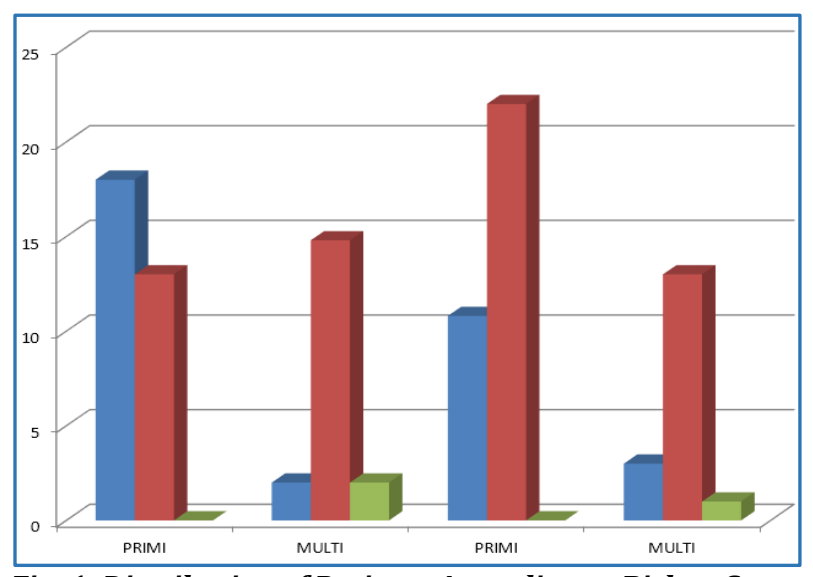

Fig. 1: Distribution of Patients According to Bishop Score

\begin{tabular}{|c|c|c|c|c|}
\hline $\begin{array}{c}\text { Duration } \\
\text { of Prom in } \\
\text { Hours }\end{array}$ & \multicolumn{2}{|c|}{ Study Group } & \multicolumn{2}{c|}{ Control Group } \\
\cline { 2 - 5 } & PRIMI & MULTI & PRIMI & MULTI \\
\hline$<3$ & 13 & 5 & 8 & 7 \\
\hline $3-6$ & 15 & 14 & 19 & 10 \\
\hline$>6$ & 3 & - & 6 & - \\
\hline Total & $\mathbf{3 1}$ & $\mathbf{1 9}$ & $\mathbf{3 3}$ & $\mathbf{1 7}$ \\
\hline $\begin{array}{c}\text { Mean } \\
\text { Duration }\end{array}$ & $3.62 \pm 2.38$ & $3.42 \pm 2.81$ & $3.23 \pm 1.82$ & $4.45 \pm 2.22$ \\
\hline \multicolumn{4}{|c|}{ Table 2: Duration of PROM in Hours } \\
\hline
\end{tabular}

$P$ value $=0.8354 \mathrm{NS} \quad \mathrm{P}$ value $=0.0574 \mathrm{NS}$

Mean duration of PROM in PRIMI patients of study group$3.62 \pm 2.38$. Mean duration of PROM in MULTI patients of study group - $3.47 \pm 2.81$. Mean duration of PROM in PRIMI patients of control group - 3.23 \pm 1.82 . Mean duration of PROM in MULTI patients if control group $-4.45 \pm 2.22$.

Most patients had PROM for 3-6 hrs. in study as well as control group. Only 3 and 6 patients had PROM for $>6$ hrs. in study and control group respectively. Hence, duration of PROM is not significant in both the groups.

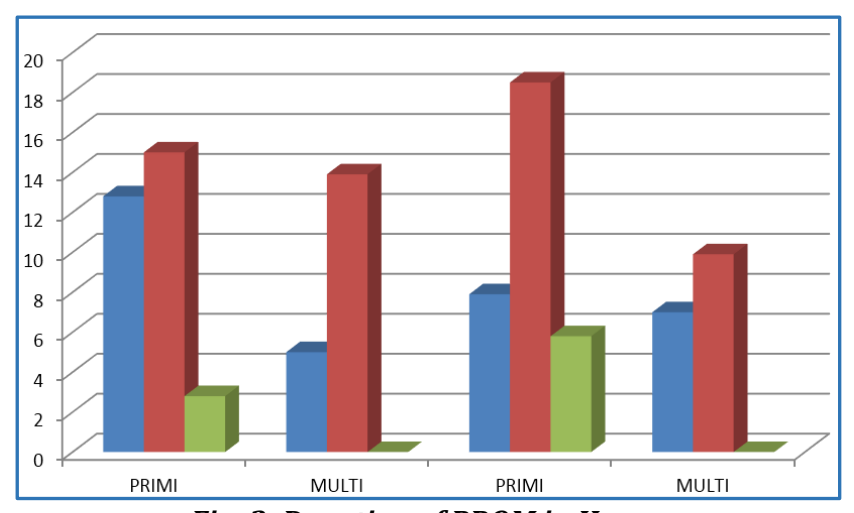

Fig. 2: Duration of PROM in Hours 


\begin{tabular}{|c|c|c|c|c|}
\hline \multirow{2}{*}{$\begin{array}{c}\text { Induction } \\
\text { Delivery } \\
\text { Interval } \\
\text { (Hrs.) }\end{array}$} & PRIMI & Multi & PRIMI & Multi \\
\cline { 2 - 5 } & & & & \\
\hline$<8$ & 4 & 7 & 3 & 3 \\
\hline $8-12$ & 11 & 11 & 2 & 10 \\
\hline $12-16$ & 14 & 01 & 7 & 3 \\
\hline $16-20$ & 02 & - & 15 & 0 \\
\hline $20-24$ & - & - & 6 & 0 \\
\hline$>24$ & - & - & 0 & 01 \\
\hline Total & $\mathbf{3 1}$ & 19 & 33 & 17 \\
\hline \begin{tabular}{c} 
Avg. \\
Induction \\
Delivery \\
\cline { 2 - 5 } Interval
\end{tabular} & $11.25 \pm 2.96$ & $7.98 \pm 2.04$ & $15.80 \pm 4.72$ & $10.83 \pm 4.87$ \\
\hline \multicolumn{4}{|l|}{ Table 3: Induction-Delivery Interval in Both Groups } \\
\hline
\end{tabular}

Mean induction delivery interval in study group is $10.01 \pm 3.08 \mathrm{hrs}$. and mean induction delivery interval in control group is $14.15 \pm 5.30 \mathrm{hrs}$.

Total 22 patients in study group has induction delivery interval between 8-12 hrs. in comparison to 12 patients of control group. Total 15 patients study group had induction delivery interval between $12-16 \mathrm{hrs}$. as compared to 10 patients in control group.

It is clear from this table that misoprostol decreases the induction delivery interval in study group.

\begin{tabular}{|c|c|c|c|c|}
\hline \multirow{2}{*}{$\begin{array}{c}\text { Mode of } \\
\text { Delivery }\end{array}$} & \multicolumn{2}{|c|}{ Study Group } & \multicolumn{2}{c|}{ Control Group } \\
\cline { 2 - 5 } & Number & Percent & Number & Percent \\
\hline Vaginal & 32 & 64 & 35 & 70 \\
\hline LSCS & 14 & 28 & 12 & 24 \\
\hline Forceps & 04 & 08 & 03 & 06 \\
\hline Total & $\mathbf{5 0}$ & $\mathbf{1 0 0}$ & $\mathbf{5 0}$ & $\mathbf{1 0 0}$ \\
\hline \multicolumn{6}{|r}{ Table 4: Showing Mode of Delivery in Each Group } \\
\hline
\end{tabular}

Pearson's chi square $=0.4312 ; \mathrm{df}=2 ; \mathrm{p}$ value $=0.806$, not significant.

This table shows the mode of delivery in both control and study group. It shows that vaginal delivery is main mode of delivery in both study and control group (64\% and 70\% respectively).

$28 \%$ of patients in study group and $24 \%$ in control group had caesarean section as mode of delivery; $8 \%$ in study group and $6 \%$ in control group had instrumental delivery. From this it is clearly evident that there is not much of difference in mode of delivery in both the groups.

\begin{tabular}{|c|c|c|c|c|}
\hline \multirow{2}{*}{$\begin{array}{c}\text { Apgar Score } \\
\text { 1 Min. }\end{array}$} & \multicolumn{2}{|c|}{ Study Group } & \multicolumn{2}{c|}{ Control Group } \\
\cline { 2 - 5 } & Number & Percent & Number & Percent \\
\hline$<7$ & 23 & 56 & 15 & 30 \\
\hline$>7$ & 27 & 54 & 35 & 70 \\
\hline Total & $\mathbf{5 0}$ & $\mathbf{1 0 0}$ & $\mathbf{5 0}$ & $\mathbf{1 0 0}$ \\
\hline \multicolumn{2}{|c}{ Table 5: Showing Apgar Score at 1 Min } \\
\hline
\end{tabular}

Pearson's chi square $=2.7165 ; \mathrm{df}=1 ; \mathrm{p}$ value $=0.0999$, NS.

$56 \%$ of babies in study group had Apgar score pf $<7$ in study group and $30 \%$ of them had Apgar score $<7$ in control group; $54 \%$ of babies had Apgar score of $>7$ in study group and
$70 \%$ of them had Apgar score $>7$. It is statistically not significant.

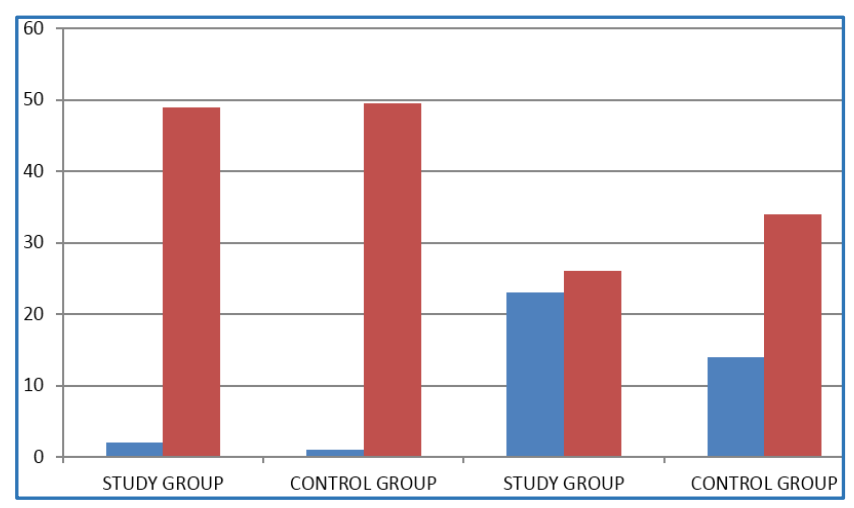

Fig. 3: Showing Apgar Score at 1 and 5 Mins

\section{DISCUSSION}

The induction to delivery interval was significantly shorter in study group $11.25 \pm 2.6$ hours in primi as compared to $15.80 \pm 4.72 \mathrm{hrs}$. in primi in control group. In multi it was $7.98 \pm 2.04 \mathrm{hrs}$. in study group as compared to $10.83 \pm 4.87 \mathrm{hrs}$. in control group. Women in study group required on an average 3 doses of 25 microgram misoprostol tablets.

As indicated in our study (induction delivery interval$10.01 \pm 3.08 \mathrm{hrs}$. in study group and $14.15 \pm 5.30$ hours in control group), oral misoprostol decreases the induction delivery interval. Similar studies carried out by Benett KA et al, Cheung PC et al, Datta MR et al, Shetty A et al have also indicated similar results in various doses.

In our study, PROM delivery interval was significantly less in study groups as compared to controls in both primi and multipara patients. These results are in agreement with other studies published in the literature that is Ozden et al, Shetty et al, Cheung et al, Datta MR et al, Frohn WE et al.

In our study, all the patients (100\%) of oral misoprostol group delivered within 24 hours of induction as compared to $66 \%$ in pitocin group. Shetty et al reported that $72 \%$ of women induced with misoprostol delivered within 24 hours of PROM compared to only $26.9 \%$ in control group. Chang et al also reported that $50 \%$ of women delivered within 24 hours of PROM. Datta et al reported that $80 \%$ of women induced with misoprostol delivered within 24 hours of PROM.

In our study, patients of oral misoprostol and pitocin group had an LSCS rate of $28 \%$ and $24 \%$ respectively ( $\mathrm{p}=0$ 806 , not significant). In our study, caesarean rate was high in both study and control group as compared with other studies. Indication of LSCS was similar in both groups in our study, i.e. foetal distress, non-progress of labour, CPD and deep transverse arrest.

In our study there was no difference in maternal secondary outcomes including caesarean birth, infection, maternal satisfaction in labour, perineal trauma, manual removal of placenta or gastrointestinal effects. This is in accordance with the studies of Datta MR et al, ${ }^{8}$ Cheung et al, 9 Mozurkewich et al, ${ }^{10}$ Krishnamma et al, ${ }^{11}$ Ozden et al, ${ }^{12}$ Krupa et $\mathrm{al}^{13}$ and Shetty et al. ${ }^{14}$

In our study group, 23 (46\%) of the new-borns had an Apgar score of $<7$ at 1 minute as compared to $15(30 \%)$ in control group. This is not statistically significant.

Slightly higher incidence of meconium staining was found in study group as compared to control group (30\% vs 
$22 \%$ ), which was not significant. This meconium staining may be attributed to misoprostol metabolites causing stimulation of foetal bowel activity or contraction abnormality. Since all women in the studies were induced for high risk factors like postdatism, oligohydramnios, PROM, etc. Misoprostol alone cannot be responsible for meconium staining liquor.

In the study $20 \%$ of babies went to PBU as compared to $14 \%$ in control group, which is not significant. This is probably because more babies delivered within 24 hours of PROM in the study group as compared to those managed by oxytocin method. The average stay was significantly high in control group as compared to study group $(3.3 \pm 1.30$ days in control group). The average stay in nursery was higher in the group managed conservatively ( 6.4 vs 3.5 days; $S E(d)=0.5$ ).

Neonatal outcome and admissions to neonatal intensive care unit were not different, but duration of stay in PBU was more in oxytocin group.

In conclusion misoprostol is a prostaglandin E1 analogue, which is rapidly absorbed after oral administration. It has uterotonic and cervical ripening properties in a dose of 25 micrograms in cases of PROM and at term it reduces the induction delivery interval in turn decreases the complications of both the mother and baby.

\section{CONCLUSION}

1. Oral misoprostol is more effective than IV oxytocin for induction of labour in PROM.

2. Misoprostol is having shorter induction delivery interval and shorter PROM delivery interval as compared to oxytocin.

3. Maternal morbidity was found to be less in misoprostol group than the control group as evidenced by decrease in incidence of chorioamnionitis and sepsis in mothers.

4. Neonatal morbidity was found to be decreased in misoprostol group than the control group as evidenced by decrease in average duration of stay in PBU for babies, meconium staining of liquor and total number of $\mathrm{PBU}$ admissions.

\section{REFERENCES}

1. Sperling LS, Schnatz AL, Wahlin A, et al. Management of prelabour rupture of membranes at term. A randomized study. Acta Obstet Gynaecol scand 1993;72(8):627-32.

2. Natale $\mathrm{R}$, Milne $\mathrm{K}$, Campbell MK, et al. Management of premature rupture of membranes at term: randomized trial. Am J Obstet Gynaecol 1994;171(4):936-9.
3. Duff P. Premature rupture of membranes of term. N Engl J Med 1996;334:1053-4.

4. Fayez JA, Hasan AA, Hoans HS, et al. Management of premature rupture of membranes. Obstet Gynaecol 1978;52(1):17-21.

5. Guise JM, Duff P, Christian JS. Management of term patients with premature rupture of membranes and unfavourable cervix. Am J perinatol 1992;9(1):56-60.

6. Granstrom L, Ekman G, Ulmsten U. Cervical ripening and labour induction with vaginal application of $\mathrm{PGE}_{2}$ in suppositories in term pregnant women with premature rupture of amniotic membranes and unfavourable cervix. Acta Obstet Gynaecol Scand 1987;66(5):429-31.

7. Goeschen K. Premature rupture of membranes near term: induction of labour with endocervical prostaglandin $\mathrm{E}_{2}$ gel or intravenous oxytocin. Am J Perinatol 1989;6(2):181-4.

8. Datta MR, Kabiraj M. Induction of labour with oral misoprostol in women with premature rupture of membranes at term. J Obstet Gynaecol India 2007;57(6):505-8.

9. Cheung PC, Yeo EL, Wong KS, et al. Oral misoprostol for induction of in women with premature rupture of membranes at term: a randomized trial. Acta Obstet Gynaecol Scand 2006;85(9):1128-33.

10. Mozurkewich E, Horrocks J, Deley S, et al. The MisoPROM study: a multicenter randomizes comparison oral misoprostol and oxytocin for premature rupture of membranes at term. Am J Obstet Gynaecol 2003;189(4):1026-30.

11. Krishnamma BS, Sundari A, Naidu IS. Evaluation of new drug misoprostol for induction of labour. J Obstet Gynaecol India 2002;52:64-6.

12. Ozden S, Delikara MN, Avci A, et al. Intravaginal misoprostol versus expectant management is premature rupture of membranes with low bishops' scores at term. Int J Gynaecol Obstet 2002;77(2):109-15.

13. Krupa G, Cecatti JG, Guiltherme J, et al. Misoprostol versus expectant management in premature rupture of membranes at term. BJOG 2005;112(9):1284-90.

14. Shetty A, Stewart K, Stewav G, et al. Active management of term prelabour rupture of membranes with oral misoprostol. BJOG Int J Obst and Gynaec 2002;109(12):1354-8. 